\title{
LETRAMENTO ACADÊMICO: A CONSTRUÇÃO DE PARÁFRASES EM RESENHAS
}

\author{
Victoria Wilson (UERJ) \\ victoriawilson@superig.com.br \\ Adriana Rodrigues Abreu (UERJ) \\ adrianarodriguess@yahoo.com.br
}

\section{Introdução}

Essa pesquisa insere-se nos estudos sobre letramento especificamente o letramento acadêmico. Privilegia-se a visão de modelo ideológico de letramento defendida por Street (2003) e Britto (2007). Esse modelo compreende o letramento como um conjunto de práticas socialmente construídas que envolvem a leitura e a escrita, ou seja, as habilidades de leitura e escrita consideradas em termos das práticas sociais, no que toca à inserção social das pessoas seja em suas experiências no cotidiano, seja no mercado de trabalho.

O foco da pesquisa está centrado na análise de resenhas produzidas por alunos de graduação em Letras de uma Faculdade de Formação de Professores, em aulas de produção textual, com vistas ao modo como os alunos se apropriam de outros textos (vozes) para assim (re)comporem a sua escrita, por meio da paráfrase. Toma-se como pressuposto o argumento de que há diferentes modos de ser letrado (GOULART, 2005). Mesmo em contextos, altamente ritualizados como o acadêmico (WILSON, 2005), que preveem uma escrita homogênea e mais padronizada de acordo com os princípios pautados na racionalidade, objetividade e cientificidade, entende-se a escrita como heterogeneamente constituída e permeada por diferentes vozes (BAKHTIN, 2003, 1993 e CORREAA, 2004).

Como o letramento acadêmico envolve a articulação entre o saber-dizer e o saber fazer (MATENCIO, 2006), conclui-se, de acordo com Bortoni-Ricardo (2001), que há várias tarefas de ordem cognitiva, linguística e social envolvidas nesse processo: se, por um lado, constituem o saber-dizer/saber-fazer, ou seja, as habilidades linguísticas e discursivas implicadas no monitoramento estilístico, cobradas pelos professores e pela comunidade acadêmica, por outro, concorrem para a produção de conhecimento (especializado, no ca- 
so) e para a expansão de competências em prol da formação profissional de qualidade (que depende também em grande parte das práticas sociais).

Como a escrita acadêmica pressupõe, então, a articulação teórica e metodológica e a apropriação (e reapropriação) de outros textos e vozes, a escolha da paráfrase - como recorte da análise - contribui para o "desvendamento" da natureza dialógica do discurso (Bakhtin, 2003) ou, em outras palavras, para as diferentes vozes que podem ser ouvidas nos textos dos alunos. Segundo Hilgert (1993), a paráfrase é uma atividade linguística de reformulação, sendo considerada, na perspectiva discursiva, um processo polifônico. Esse processo de reformulação pode avançar da simples esfera da reprodução para a reconstrução criativa de novos sentidos.

De acordo com Meserani (2008, p. 98), "a paráfrase sempre se remete a uma obra anterior para reafirmá-la, esclarecê-la", aproximando-se, na maior parte das vezes, da reprodução (no sentido da repetição). O autor divide a paráfrase em duas categorias: paráfrase reprodutiva - em que o aluno pode parafrasear um texto e reproduzir apenas aquilo que está sendo dito ou paráfrase criativa - em que o aluno pode avançar em busca de novos sentidos/significados, contribuindo para uma nova reflexão acerca do assunto abordado. Diz o autor: que a paráfrase reprodutiva "trabalha basicamente no eixo de substituições semânticas, da sinonímia" (p. 100), enquanto na paráfrase criativa "o texto se desdobra e se expande em novos significados" (p. 108).

Compreende-se, no entanto, de acordo com a perspectiva aqui assumida, que qualquer direção realizada pelo aluno, em seu texto, evidenciará, além da relação semântica, uma relação dialógica com o texto parafraseado.

\section{Linha teórica e metodológica da pesquisa}

Esta pesquisa está fundamentada no paradigma interpretativista, sendo de natureza qualitativa, uma vez que os textos são considerados em sua dimensão discursiva. Segundo Bortoni-Ricardo (2008, p. 34), "a pesquisa qualitativa procura entender, interpretar fenômenos sociais inseridos em um contexto". 
A pesquisa está situada num contexto de formação de professores de uma faculdade localizada no município de São Gonçalo, Rio de Janeiro. O material de análise é composto por artigos e resenhas, produzidos por alunos de Letras em aulas de Técnicas de Comunicação e Expressão (TCE), coletadas na época em que ainda vigorava o currículo antigo (2006) e a disciplina era ministrada no último período do curso de Letras ( $8^{\circ}$ período), com uma carga horária semanal de 2 horas e 30 minutos. A disciplina, como o nome sugere, está voltada para a produção de textos acadêmicos e era ministrada com o intuito de desenvolver habilidades e competências na redação desses gêneros.

Escolhemos o gênero resenha para a realização da análise por ser bastante frequente nos cursos de graduação. Além disso, essa escolha se deu pela motivação em observar a construção de opinião/críticas relativamente ao livro resenhado, levando em conta a polifonia como constitutiva de todo discurso.

Por isso, a paráfrase foi escolhida com o objetivo de perceber como os alunos se apropriam das vozes alheias e como esse movimento traduz as formas de se lidar com o conhecimento e com as convenções do gênero e do contexto. Oliveira (2005, p. 106), baseado na NBR 6028/2003 da ABNT, apresenta a seguinte sequência como passos estruturais para a composição de uma resenha: referência bibliográfica, credenciais da autoria, resumo da obra, conclusões do autor, quadro de referência do autor, apreciação crítica do resenhista e indicações da obra. No que toca ao letramento acadêmico, Bortoni-Ricardo (2000, p. 126) salienta as seguintes propriedades:

[O letramento acadêmico] inclui a capacidade de analisar o texto, identificando-lhe as partes constitutivas, hierarquizando as ideias ali avançadas e reconhecendo o processo de progressão ou continuidade temática, inclusive as reiterações e digressões. Dessa forma compreende a capacidade de produzir paráfrases, resumos, roteiros, esquemas, etc. Compreende também a capacidade de contextualizar o texto em função das condições que presidiram sua produção, tais como sua inserção no momento sócio-histórico e no estado da arte da tradição epistemológica em que se inscreve, reconhecendo o quadro conceitual que lhe serve de matriz e a polifonia que dele emana.

Além das competências linguísticas e normativas a que o aluno precisa se adequar e também se apropriar, a orientação bakhtiniana aponta para o princípio dialógico do discurso, ou seja, todo texto 
traz marcas de outros textos e de outras vozes. Nesse sentido, buscase observar em que medida o recurso parafrástico, quando articulado ao saber-dizer/saber-fazer acadêmico, constitui-se como: simples repetição (cópia) do texto original de forma pouco ou não articulada na interação entre os textos (texto-fonte e resenha) ou como um processo mais interativo, demonstrando maior envolvimento e consequentemente revelando maior participação na construção de conhecimento e autoria. Como avaliar uma boa resenha? Aquela que se ajusta às normas contextuais, mas nada acrescenta? Ou aquela que revela participação mais ativa em prol da construção do conhecimento?

Por essa razão, para a análise contribuições teóricas que nos ajudaram: (i) a olhar o texto em sua heterogeneidade, como em Bakhtin (2006) e Corrêa (2004); (ii) a entender que o letramento está articulado com a construção do conhecimento (BRITTO, 2007); (iii) a observar que a escrita dos alunos reflete os saberes a ela articulados, seja o conhecimento respaldado no cotidiano, seja o de natureza científica (LOPES, 1999); (iv) a compreender a formação, ainda que embrionária, do discurso e do conhecimento científico (Possenti, 2004); (v) a compreender a paráfrase nesse universo como diálogo entre a palavra de autoridade (representada pelo discurso e saber acadêmico e pela obra sobre a qual o aluno faz a resenha) e a palavra autônoma (a escrita mais criativa em direção à autonomia), conforme Bakhtin (1993).

Como estamos a investigar os procedimentos parafrásticos associados à construção de pontos de vista e conhecimento, para a análise das resenhas destacamos: (a) o parágrafo correspondente ao resumo da obra como um todo, (b) os parágrafos que resumem cada capítulo do livro resenhado e (c) o parágrafo de conclusão, que contém as apreciações críticas dos alunos.

Fazem parte dessa análise duas resenhas do livro, Pedagogia da autonomia: saberes necessários à prática educativa, de Paulo Freire. Essas resenhas serão interpretadas, observando-se o modo como a paráfrase foi elaborada pelo aluno em seu diálogo com o texto-fonte: de um lado, síntese das ideias, de outro, apreciação do livro.

Os textos produzidos pelos alunos são extensos e, por esse motivo, não foram colocados na sua íntegra nesse trabalho. Escolhemos apenas as partes relevantes para essa análise, mantendo-se a 
forma original tal qual foi escrita. Para a análise, identificamos as resenhas como A e B. É na tensão entre o que se espera de uma resenha e do que se apresenta como uma resenha nos limites de um enunciado possível que esboçaremos a análise.

\section{A construção de resenhas acadêmicas}

Conforme a orientação apresentada na metodologia, destacaremos primeiramente excertos das duas resenhas (A e B) de modo que contemplem os parágrafos que ou sintetizam a obra como um todo ou aqueles que resumem cada capítulo da obra, mais o parágrafo de conclusão, destinado à apreciação crítica.

(a) Fragmentos correspondentes ao resumo do texto fonte, no momento em que descrevem o referido livro:

\begin{tabular}{|l|l|}
\hline \multicolumn{1}{|c|}{ RESENHA A } & \multicolumn{1}{c|}{ RESENHA B } \\
\hline O livro "Pedagogia da autonomia", de & Neste livro, é abordada a questão da \\
Paulo Freire, trata das práticas pedagó- & formação de professores ligadas à prá- \\
gicas, de como o professor tem que li- & tica educativa progressista em favor da \\
dar com os seus alunos e fazer com que & autonomia dos educandos, analisando \\
haja o ensino-aprendizagem. Ele nos & os saberes considerados fundamentais \\
mostra, através do seu livro, várias & ao exercício docente. Dividida em três \\
maneiras de transformar o ambiente, & capítulos, a obra traz em seu conteúdo \\
muitas vezes "chato", da sala de aula, & uma forte carga de otimismo e espe- \\
em um lugar de descobertas e sonhos. & rança (...). \\
\hline
\end{tabular}

(b) Fragmentos correspondentes ao resumo do $1^{\circ}$ capítulo do livro, "Não há docência sem discência":

\begin{tabular}{|c|c|}
\hline RESENHA A & RESENHA B \\
\hline $\begin{array}{l}\text { "Ensinar exige respeito aos saberes dos educan- } \\
\text { dos". Uma afirmação muito atual do autor, pois } \\
\text { vivemos em uma sociedade desigual socialmen- } \\
\text { te, em que precisamos respeitar que nossos dife- } \\
\text { rentes alunos terão diferentes realidades e que } \\
\text { para atender as espectativas de cada um deles se- } \\
\text { rá preciso um respeito a essas diferenças que a- } \\
\text { carretam a diferença também na forma de apren- } \\
\text { der. }\end{array}$ & $\begin{array}{l}\text { No primeiro capítulo, Freire } \\
\text { aponta a necessidade de se } \\
\text { assumir a educação como um } \\
\text { processo dialógico, em que o } \\
\text { ensino não está ligado apenas } \\
\text { ao professor, assim como a } \\
\text { aprendizagem não é exclusi- } \\
\text { vamente do aluno. }\end{array}$ \\
\hline
\end{tabular}


c) Fragmentos correspondentes ao resumo do $2^{\circ}$ capítulo do livro "Ensinar não é transferir conhecimento":

\begin{tabular}{|c|c|}
\hline RESENHA A & RESENHA B \\
\hline $\begin{array}{l}\text { No capítulo 2, ele nos diz que "Ensinar } \\
\text { não é transferir conhecimentos". Quando } \\
\text { entender que quando estamos à frente de } \\
\text { uma turma, escrevendo no quadro negro, } \\
\text { não estamos transferindo conhecimentos? } \\
\text { Essa teoria, defendida por Paulo me con- } \\
\text { funde um pouco, pois não compreendo es- } \\
\text { sa criação de uma atividade pedagógica } \\
\text { própria que não me leve a simplesmente } \\
\text { transferir conhecimento. }\end{array}$ & $\begin{array}{l}\text { No segundo capítulo, em cujo título } \\
\text { já se observa a sua relevância, "en- } \\
\text { sinar não é transferir conhecimen- } \\
\text { tos", é apresentada a noção do ina- } \\
\text { cabamento do ser humano, da qual } \\
\text { o professor crítico deve ter consci- } \\
\text { ência, pois somente a partir desta o } \\
\text { homem se torna educável. Deve-se } \\
\text { compreender a história como um } \\
\text { tempo de possibilidades, não de de- } \\
\text { terminismos. }\end{array}$ \\
\hline
\end{tabular}

(d) Fragmentos correspondentes ao resumo do $3^{\circ}$ capítulo do livro, "Ensinar é uma especificidade humana":

\begin{tabular}{|l|l|}
\hline \multicolumn{1}{|c|}{ RESENHA A } & \multicolumn{1}{c|}{ RESENHA B } \\
\hline $\begin{array}{l}\text { Não houve re- } \\
\text { sumo do tercei- } \\
\text { ro capítulo na } \\
\text { presente rese- } \\
\text { nha. }\end{array}$ & $\begin{array}{l}\text { No terceiro capítulo, o ato de educar é reconhecido como es- } \\
\text { pecíco da espécie humana, exigindo segurança, competência, } \\
\text { preciso. Ensinar, generosidade e convicção de que mudar é } \\
\text { mundo e, consequentemente, de realizar mudanças efetivas na } \\
\text { sociedade. }\end{array}$ \\
\hline
\end{tabular}

(e) Fragmentos correspondentes ao parágrafo de conclusão das respectivas resenhas:

\begin{tabular}{|c|c|}
\hline RESENHA A & RESENHA B \\
\hline $\begin{array}{l}\text { É claro que o livro é muito bom e cla- } \\
\text { ro, porém é difícil para por em práti- } \\
\text { ca, pois a realidade é muito diferente } \\
\text { da que está no livro. Atualmente é um } \\
\text { pouco difícil seguir. (...) O livro, de } \\
\text { um modo geral é maravilhoso, se só } \\
\text { pudéssemos sonhar, sem enfrentar a } \\
\text { realidade. (...) Porém o livro deverá } \\
\text { ser encarado como uma tentativa de }\end{array}$ & $\begin{array}{l}\text { A linguagem extremamente filosófica e, } \\
\text { por vezes, repetitiva deste livro, torna a } \\
\text { leitura difícil e enfadonha, configuran- } \\
\text { do-se num obstáculo à compreensão por } \\
\text { parte de "todos os educadores e educan- } \\
\text { do" a quem a obra se destina. Contudo, } \\
\text { é impossível não reconhecer a impor- } \\
\text { tância das ideias de Paulo Freire, cuja } \\
\text { pedagogia respeita os educandos (...) }\end{array}$ \\
\hline
\end{tabular}

Fazendo-se uma comparação, cada aluno, na condição de escrevente, elabora a resenha de acordo com seu estilo, adequando-se 
ao gênero em particular, utilizando-se das convenções linguísticas e discursivas que sugerem a expressão diferentes modos de ser letrado. $\mathrm{Na}$ resenha A, ao parafrasear a obra, há uma tentativa do escrevente em construir novos sentidos para o seu texto, embora a sua escrita esteja pautada apenas em um dizer que reflete experiências do cotidiano ou crenças baseadas no senso comum. Na resenha B, ao contrário, as paráfrases se encontram no campo reprodutivo, de substituições semânticas: a maior parte da resenha é composta por cópias de fragmentos específicos da obra, indicando menos monitoramento estilístico e, consequentemente, um projeto de autoria mais enfraquecido ainda que incorpore traços característicos, termos, expressões e estrutura da linguagem científica.

Pode-se dizer que, na resenha A, o aluno/escrevente parece ter se posicionado de modo a deixar a sua voz se manifestar. Na resenha B, entretanto, a voz do aluno se aproxima do discurso de Paulo Freire, de forma a reproduzir o já-dito. Cabe ressaltar que, embora de formas diferenciadas, em ambas as resenhas houve a criação de um novo enunciado, pois, segundo Bakhtin (1990, p. 147), "aquele que apreende a enunciação de outrem não é um ser mudo, privado de palavras, mas ao contrário, um ser cheio de palavras interiores".

Como definir letramento acadêmico nesses termos?

O escrevente da resenha A não vê relação entre as propostas apresentadas por Paulo Freire com a sua verdadeira prática profissional. Sendo assim, há, no decorrer de todo o seu texto, uma tensão entre as propostas apresentadas por Freire e a experiência de vida desse aluno. Esta resenha se estabelece, basicamente, pelo embate existente entre a realidade (experiência de vida do aluno - palavra própria) e a utopia (discurso de Paulo Freire - palavra de autoridade). O último parágrafo sintetiza de modo bem claro o conflito que o texto de Freire provoca no aluno: "O livro, de um modo geral é maravilhoso, se só pudéssemos sonhar, sem enfrentar a realidade. (...) Porém o livro deverá ser encarado como uma tentativa de mudança, mas só uma tentativa".

Segundo Possenti (2004), baseando-se em Granger (1968), a eliminação do individual na linguagem ocorre quando há eliminação do vivido, nesse caso, especificamente, o "vivido" prevalece sobre o "científico". Haveria perda ou falta de cientificidade nesse caso? De 
acordo com Possenti, "o critério de cientificidade de um enunciado não é a verdade da proposição que ele veicula, mas seu sistema de produção" (POSSENTI, 2004, p. 238). E um dos critérios fundamentais para a distinção entre enunciados científicos dos não científicos, ainda nas palavras de Possenti, retomando Granger, seria o fato de o primeiro não estar ligado à subjetividade. No entanto, apoiando-nos em Bakhtin e no próprio Possenti, o discurso é permeado de subjetividades. "O próprio trabalho de eliminação da subjetividade é um trabalho dos sujeitos." (POSSENTI, 2004, p. 240)

Ora, o que a presença ou a tensão existente entre a palavra própria e a de autoridade se relacionam com os critérios de cientificidade em sua relação com o letramento acadêmico? No processo de letramento, os alunos vão incorporando modos de dizer da ordem do convencionalmente instituído ao mesmo tempo em que ainda mantêm o diálogo com outras formas de saber: aquelas que eles já dispõem e estão ancoradas no ouvido/lido (domínio da recepção). O problema é: como fazer a articulação entre os saberes de modo a articulá-los ao saber correspondente, aplicável no momento da textualização, conforme destaca Corrêa (2004, p. 263)?

De acordo com esse autor, os escreventes fazem representações com a e pela escrita e esta revela os lugares que eles estabelecem em suas diferentes práticas sociais (CORRÊA, 2004, p. 11); portanto, a enunciação por meio da escrita acaba por espelhar as diversas limitações e conflitos - sempre presentes nos momentos de apropriação de novos discursos. Por essa razão é que a paráfrase constitui-se nesta pesquisa um elemento importante dentro de todo o processo que a envolve e que está "regulado pela circulação dialógica do escrevente" (CORRÊA, 2004, p. 13) E, curiosamente, é, pois, segundo o autor o "aspecto dialógico da constituição do sujeito que transforma as pistas e o sujeito em individualidades.” (p. 16)

$\mathrm{O}$ emprego da primeira pessoa do singular mais à forma íntima com que se refere ao autor, no fragmento correspondente ao capítulo 2: "Essa teoria, defendida por Paulo, me confunde um pouco" -, demonstra como o aluno vai construindo seus pontos de vista na elaboração de sua resenha. Ao lidar com a teoria proposta pelo autor, o aluno traz marcas de subjetividade, revelando a presença do discurso interior no processo de gênese da escrita, conforme Smolka (2000) 
argumenta fazendo referências à alfabetização. Ao lidar com a palavra de autoridade em relação à palavra própria, o escrevente demonstra a oscilação entre um dizer de ordem institucional e um de ordem subjetiva tal qual um relato de experiência ou uma narrativa do tipo espontânea, como na continuação do fragmento:

Quando entender que quando estamos à frente de uma turma, escrevendo no quadro negro, não estamos transferindo conhecimentos? Essa teoria, defendida por Paulo me confunde um pouco, pois não compreendo essa criação de uma atividade pedagógica própria que não me leve a simplesmente transferir conhecimento.

Se retornarmos à discussão entre enunciados científicos e não científicos, poderemos perceber que o problema (se é de fato um problema) não reside na eliminação da subjetividade, mas na do vivido. Assim, a questão que se coloca é: como enunciado caracterizado como relato de experiência pessoal, a resenha ressalta o vivido ou uma possibilidade de experiência a ser vivida. A construção parafrástica - as ideias do texto original para as ideias a serem apresentadas - expressa a ambivalência entre o questionamento realizado em termos experienciais e a expectativa de um texto adequado aos propósitos acadêmicos.

$\mathrm{O}$ escrevente da resenha $\mathrm{A}$, ao trazer à tona um conjunto de experiências próprias, mantém resistência a tudo aquilo que é diferente ou que se distancia da sua vivência, de sua prática. Como as questões levantadas por Freire são diferentes daquelas vivenciadas pelo aluno, este se mantém resistente e irredutível a mudanças ou a modificação de atitudes. A palavra de autoridade, representada pelo discurso de Freire, parece encarnar o discurso utópico, idealista, do qual o aluno se distancia para assumir, então, uma palavra própria, constituída como réplica, como diálogo com a autoridade (tensão entre a palavra de autoridade e a palavra própria).

Lopes (1999), ao trabalhar com os diferentes conhecimentos que estão associados à educação destaca a importância que se atribui ao saber erudito, porém argumenta que é preciso compreendê-los não como "saberes neutros, purificados de suas marcas de classe pelo tempo e pela tradição." É preciso "propiciar seu diálogo com os saberes populares, os saberes cotidianos, em mútuo questionamento" (LOPES, 1999, p. 80). 
Quanto à resenha $\mathrm{B}$, percebe-se uma tendência a resumir o texto fonte. As paráfrases utilizadas nesta resenha estão muito mais no campo da reprodução do que no da criação. O escrevente, ao produzir uma paráfrase, acrescenta algumas palavras em seu texto e, às vezes, modifica outras, mas o sentido permanece o mesmo, praticamente igual ao texto original. Algumas vezes, segundo Meserani, há na paráfrase reprodutiva uma repetição literal de um trecho (MESERANI, 2008, p. 100). É o que acontece com um dos fragmentos mais importantes do livro, em que Paulo Freire diz ser importante "reconhecer que a História é tempo de possibilidades e não de determinismo" (FREIRE, 1996, p. 19), e o aluno assim reescreve esse trecho: "Deve-se compreender a história como um tempo de possibilidades, não de determinismos". Esse tipo de paráfrase "trabalha basicamente no eixo de substituições semânticas, da sinonímia" (MESERANI, 2008, p. 100), sendo muito frequente na resenha B.

Nesta resenha, o aluno, mais uma vez, cria uma paráfrase reprodutiva, ao resumir o último capítulo do livro, pois há uma referência explícita ao índice da obra resenhada. Ao observarmos o índice da obra, é visível a semelhança entre este e o texto escrito pelo aluno-escrevente, como se esse parágrafo tivesse sido formulado de modo a alinhavar cada item do índice. É importante ressaltar, que no processo de construção do letramento acadêmico, por meio da leitura aqui proposta, esse aluno estaria aquém do esperado. Segundo a reflexão de Matencio (2006) sobre letramento acadêmico, não basta o aluno saber dizer é preciso também saber fazer. Embora demonstre saber como se organiza uma resenha, o aluno demonstra pouca habilidade para construir opiniões próprias.

Parece que o procedimento parafrástico nesta resenha se enquadra na concepção que Sant'anna atribui à paráfrase. Para este autor, "a paráfrase é um discurso sem voz, pois quem está falando está falando o que o outro já disse. É uma máscara que se identifica totalmente com a voz que fala atrás de si" (SANT'ANNA, 2007, p. 29)

Na resenha B, só foi possível observar com mais clareza a avaliação da obra de Freire nos últimos parágrafos do texto, uma vez que o escrevente dessa resenha parece ter privilegiado as regras de composição desse gênero sobre os demais aspectos que o compõem. Ao concluir o texto, o escrevente fala das dificuldades que encontrou 
ao realizar a leitura, de modo distinto do escrevente da resenha A, pois aqui o escrevente não se coloca no plano das experiências vividas: a dificuldade apontada por ele tem origem na própria obra. Por considerar a linguagem "filosófica" e até "repetitiva" a leitura passa a ser considerada por ele "difícil e enfadonha", dois adjetivos com um valor apreciativo negativo. Porém, o operador argumentativo "contudo" seguido de um predicado cristalizado "é impossível" amortece a crítica negativa e expressa a importância das ideias de Freire. Uma avaliação dessa natureza não oferece credibilidade, uma vez que está pautada num critério eminentemente subjetivo, sem fundamento que o sustente. Esse tipo de subjetividade distancia-se do critério científico e revela ainda o quanto o escrevente está distante das formas de ser academicamente letrado, embora procure formalmente delas se aproximar.

Enfim, o modo como os alunos se apropriam de outro discurso demonstra um saber ainda incipiente se comparado, no processo de construção do letramento acadêmico, ao rigor científico exigido pela academia. Percebe-se, ora um dizer da ordem do cotidiano, prevalecendo a experiência vivida, ora um dizer institucional, mas afastando-se da construção da palavra interiormente persuasiva, no momento das articulações teóricas e metodológicas como expõe Bortoni-Ricardo (2001, p. 125):

O letramento refere-se ao conjunto de estratégias usadas na redação e leitura de variados gêneros textuais, especialmente os empregados na produção e divulgação do conhecimento acadêmico. Entre essas estratégias relevamos a capacidade de elaborar um texto levando em conta os objetivos do autor e as expectativas dos interlocutores ou leitores.

\section{Considerações finais}

Embora a produção textual dos alunos já revele certas propriedades formais quanto ao modo de elaborar (fazer) textos acadêmicos, também demonstra como são heterogêneos os modos de produção: a escrita é o lugar da expressão, e, na academia, a apropriação de normas e saberes reflete a (des)ordem com que são transmitidos e apreendidos.

As análises realizadas mostram que as paráfrases construídas pelos alunos revelam: de um lado, um discurso criativo, embora pau- 
tado em experiências próprias, o que acaba não adquirindo valor científico, e do outro lado, um discurso reproduzindo o já-dito, máscara do texto original.

Entretanto, segundo Amorim (2004, p. 133), as enunciações não podem ser consideradas apenas como pura repetição do já-dito, pois "mesmo no caso de uma repetição, ela também seria nova: um novo contexto de enunciação constitui um novo contexto dialógico, o que produz sempre um novo sentido". Portanto, qualquer enunciado, parafrástico ou não, se levarmos em conta o princípio dialógico bakhtiniano, está sempre atrelado à presença do outro, ou seja, mantendo relações com outros enunciados e outras práticas sociais. Segundo Bakhtin, um enunciado está vinculado àqueles que, de alguma forma, o precederam ou aos que o sucederão. Ora, se considerarmos o princípio dialógico da linguagem, entenderemos que uma paráfrase jamais poderá ser considerada como um discurso sem voz, uma vez que só a escolha de determinada parte da obra para ser parafraseada e o trabalho de reformulação, por exemplo, já constituem um novo discurso, evidenciando, de alguma forma, a presença de um novo enunciador no texto.

Sendo assim, de acordo com o princípio dialógico, qualquer direção tomada pelo aluno, em seu texto, evidenciará os efeitos polifônicos que dele emanam: seja por meio de uma interação de natureza experiencial, traduzindo o vivido, seja por meio do efeito de monologização, conforme palavras de Corrêa (2004, p. 289). Nesse caso, tanto a cópia como máscara do texto original como a forma mais explícita do diálogo refletem o hiato "entre a voz representada como de fora e a outra representada com a do próprio escrevente" (CORREA, 2004, p. 289), refletindo, consequentemente, diferentes formas de assujeitamento às regras do discurso de um grupo institucional (POSSENTI, 2004, p. 240).

Embora as resenhas sejam produzidas por um único locutor, respectivamente, as análises possibilitam perceber um imbricamento de vozes, reafirmando o princípio basilar dessa pesquisa de que todo texto é polifônico/ heterogêneo. Pode-se dizer que a escrita desses alunos universitários, bem como a escrita em geral, caracteriza-se pela heterogeneidade por estar ligada ao aspecto dialógico da lingua- 
gem. E a paráfrase se constitui como um discurso de natureza polifônica, sem dúvida.

Após as análises e reflexões aqui desenvolvidas, passamos a entender o letramento como um processo que envolve tanto aspectos individuais quanto sociais. Acreditamos que o letramento ultrapassa as competências e a esfera funcional, passando a ser entendido, por nós, como processo e "atividade" discursivos de cunho dialógico.

\section{REFERÊNCIAS BIBLIOGRÁFICAS}

BAKHTIN, Mikhail. Os gêneros do discurso. In: . Estética da criação verbal. Tradução: Paulo Bezerra. 4. ed. São Paulo: Martins Fontes, 2003.

\section{UNESP, 1988.}

Marxismo e filosofia da linguagem. São Paulo: Hucitec/

. O discurso em Dostoievski. In: Problemas da poética em Dostoiévski. Tradução: Paulo Bezerra. 1. ed. bras. Rio de Janeiro: Forense Universitária, 1981.

. Questões de literatura e de estética. A teoria do romance. São Paulo: Hucitec / UNESP, 1993.

BORTONI-RICARDO, Stella Maris. A interação face a face em sala de aula e o texto mediático. In: ABRALIN: Boletim da Associação Brasileira de Linguística. Fortaleza: Imprensa Universitária/ UFC, Vol. 25, 2001.

. O professor pesquisador: introdução à pesquisa qualitativa. São Paulo: Parábola, 2008. (Estratégias de Ensino; 8)

BRITTO, Luiz Percival Leme. Contra o consenso: cultura escrita, educação, participação. Campinas: Mercado de Letras, 2003.

. Escola, ensino de língua, letramento e conhecimento. In: Calidoscópio. Caxias do Sul: Unisinos, 2007, vol. 5, n. 1

FREIRE, Paulo. Pedagogia da autonomia: saberes necessários à prática educativa. São Paulo: Paz e Terra, 1996. (Coleção leitura) 
GERALDI, João Wanderley. A diferença identifica. A desigualdade deforma. Percursos bakhtinianos de construção ética. In: FREITAS, M. T.; JOBIM E SOUZA, S., KRAMER, S. Ciências humanas e pesquisa: leituras de Mikhail Bakhtin. São Paulo: Cortez, 2003.

GOULART, Cecília. A noção de letramento como horizonte éticopolítico para o trabalho pedagógico: explorando diferentes modos de ser letrado. Projeto de pesquisa, Niterói / UFF, 2003.

HILGERT, José Gaston. Procedimentos de reformulação: a paráfrase. In: PRETI, Dino. (Org.) Análise de textos orais. Projeto de Estudo da norma linguística urbana culta de São Paulo. São Paulo: FFLCH/USP, 1993.

IVANIC, Oz. Writing and identity: the discoursal construction of identity in academic writing. Philadelphia/Amsterdam: John Benjamins Publishing, 1997.

LOPES, Alice Ribeiro Casimiro. Conhecimento escolar: ciência e cotidiano. Rio de Janeiro: EDUERJ, 1999.

MATENCIO, Maria de Lourdes M. Letramento na formação do professor. Integração a práticas discursivas acadêmicas e construção da identidade profissional. In: CORRÊA, M. L. G.; BOCH, F. (Orgs.). Ensino de língua: representação e letramento. Campinas: Mercado de Letras, 2006, p. 93-106.

MESERANI, Samir. $O$ intertexto escolar: sobre leitura, aula e redação. 5. ed. São Paulo: Cortez, 2008.

MEY, Jacob L.. As vozes da sociedade: seminários de pragmática. São Paulo: Mercado de Letras, 2001.

OLIVEIRA, Jorge Leite de. Texto acadêmico - técnicas de redação e de pesquisa científica. Petrópolis: Vozes, 2005.

POSSENTI, Sírio. Sobre a linguagem científica e linguagem comum. In: __. Os limites do discurso. 2. ed. Curitiba: Criar, 2004.

SANT'ANNA, Affonso Romano de. Paródia, paráfrase \& cia. 8. ed. São Paulo: Ática, 2007.

SOARES, Magda. Letramento: um tema em três gêneros. Belo Horizonte: Autêntica, 2001. 
STREET, Brian. Abordagens alternativas ao letramento e desenvolvimento. Teleconferência Unesco Brasil sobre 'Letramento e Diversidade'. Outubro de 2003.

WILSON, Victoria. Ser letrado no contexto acadêmico. In: MAGALHÃES, José Sueli e TRAVAGLIA, Luiz Carlos. Múltiplas perspectivas em linguística. ILEEL, UFU: Uberlândia, 2008a. (CD-ROM)

. O discurso científico e a formação do professor. In: GIL, Gloria; VIEIRA-ABRAHÃO, Maria Helena. (Orgs.). Educação de professores de línguas: os desafios do formador. São Paulo: Pontes, 2008b, p. 201-218.

. A construção discursiva e identitária na escrita acadêmica. In: ALMEIDA, Fernando Afonso; GONÇALVES, José Carlos. Interação, contexto e identidade em práticas sociais. Niterói: EDUFF, 2009, p. 95-116. 